\title{
ON THE REVERSE HARDY-TYPE INTEGRAL INEQUALITIES IN THE WHOLE PLANE WITH THE EXTENDED RIEMANN-ZETA FUNCTION
}

\author{
Michael Th. Rassias, Bicheng Yang And Andrei RaigorodskiI
}

\begin{abstract}
In the present paper, using weight functions we obtain some equivalent conditions of two kinds of the reverse Hardy-type integral inequalities with a nonhomogeneous kernel in the whole plane. The constant factors, which are related to the extended Riemann zeta function, are proved to be the best possible. In the form of applications, a few equivalent conditions of two kinds of the reverse Hardy-type integral inequalities with the homogeneous kernel in the whole plane are deduced. We also consider some particular cases.
\end{abstract}

Mathematics subject classification (2010): 26D15, 47A07.

Keywords and phrases: Hardy-type integral inequality, weight function, parameter, equivalent form, reverse.

\section{REFERENCES}

[1] G.H. Hardy, J.E. Littlewood, G. Pólya, Inequalities, Cambridge University Press, Cambridge, USA, 1934.

[2] B.C. YANG, The norm of operator and Hilbert-type inequalities, Science Press, Beijing, China, 2009.

[3] B.C. YANG, Hilbert-Type Integral Inequalities, Bentham Science Publishers Ltd., The United Arab Emirates, 2009.

[4] B.C. YANG, On the norm of an integral operator and applications, J. Math. Anal. Appl., 321(2006), 182-192.

[5] J.S. XU, Hardy-Hilbert's inequalities with two parameters, Advances in Mathematics, 36(2), 63-76.

[6] B.C. YANG, On the norm of a Hilbert's type linear operator and applications, J. Math. Anal. Appl., 325(2007), 529-541.

[7] D.M. XIN, A Hilbert-type integral inequality with the homogeneous kernel of zero degree, Mathematical Theory and Applications, 30(2)(2010), 70-74.

[8] B.C. YANG, A Hilbert-type integral inequality with the homogenous kernel of degree 0, Journal of Shandong University (Natural Science), 45(2)(2010), 103-106.

[9] L. Debnath, B.C. YAng, Recent developments of Hilbert-type discrete and integral inequalities with applications, International Journal of Mathematics and Mathematical Sciences, Volume 2012, Article ID 871845, 29 pages.

[10] Y. Hong, On the structure character of Hilbert's type integral inequality with homogeneous kernel and applications, Journal of Jilin University (Science Edition), 2017, 55(2), 189-194.

[11] M.TH. Rassias, B.C. YANG, On half-discrete Hilbert's inequality, Applied Mathematics and Computation, 220(2013), 75-93.

[12] B.C. YANG, M. KRNIĆ, A half-discrete Hilbert-type inequality with a general homogeneous kernel of degree 0, Journal of Mathematical Inequalities, 6(3)(2012), 401-417.

[13] TH.M. RAssias, B.C. YANG, A multidimensional half - discrete Hilbert - type inequality and the Riemann zeta function, Applied Mathematics and Computation, 225(2013), 263-277.

[14] M.TH. RASSIAS, B.C. YANG, On a multidimensional half - discrete Hilbert - type inequality related to the hyperbolic cotangent function, Applied Mathematics and Computation, 242(2013), 800-813.

[15] M.Th. RAssias, B.C. YANG, A multidimensional Hilbert - type integral inequality related to the Riemann zeta function, Applications of Mathematics and Informatics in Science and Engineering (N. J. Daras, ed.), Springer, New York, 417-433, 2014. 
[16] M.Th. Rassias, B. YANG, On an equivalent property of a reverse Hilbert-type integral inequality related to the extended Hurwitz-zeta function, J. Math. Inequal. 13 (2019), 315-334.

[17] Y. HONG, B. HE, B. YANG, Necessary and sufficient conditions for the validity of Hilbert type integral inequalities with a class of quasi-homogeneous kernels and its application in operator theory, J. Math. Inequal. 12 (2018), 777-788.

[18] Q. Chen, B.C. YANG, A survey on the study of Hilbert-type inequalities, Journal of Inequalities and Applications (2015), 2015:302.

[19] B.C. YANG, A new Hilbert-type integral inequality, Soochow Journal of Mathematics, 33(4)(2007), 849-859.

[20] B. HE, B.C. YANG, On a Hilbert-type integral inequality with the homogeneous kernel of 0-degree and the hypergeometric function, Mathematics in Practice and Theory, 40(18)(2010), 105-211.

[21] B.C. YANG, A new Hilbert-type integral inequality with some parameters, Journal of Jilin University (Science Edition), 46 (6)(2008), 1085-1090.

[22] B.C. YANG, A Hilbert-type integral inequality with a non-homogeneous kernel, Journal of Xiamen University (Natural Science), 48(2)(2008), 165-169.

[23] Z. ZENG, Z.T. XIE, On a new Hilbert-type integral inequality with the homogeneous kernel of degree 0 and the integral in whole plane, Journal of Inequalities and Applications, Vol. 2010, Article ID 256796, 9 pages.

[24] A.Z. WANG, B.C. YANG, A new Hilbert-type integral inequality in whole plane with the nonhomogeneous kernel, Journal of Inequalities and Applications, Vol. 2011, 2011: 123.

[25] D.M. XIN, B.C. YANG, A Hilbert-type integral inequality in whole plane with the homogeneous kernel of degree -2, Journal of Inequalities and Applications, Vol. 2011, Article ID 401428, 11 pages.

[26] B. HE, B.C. YANG, On an inequality concerning a non-homogeneous kernel and the hypergeometric function, Tamsul Oxford Journal of Information and Mathematical Sciences, 27(1)(2011), 75-88.

[27] B. YANG, A reverse Hilbert-type integral inequality with a non-homogeneous kernel, Journal of Jilin University (Science Edition), 49(3)(2011), 437-441.

[28] Z.T. XIE, Z. ZENG, Y.F. SUN, A new Hilbert-type inequality with the homogeneous kernel of degree -2, Advances and Applications in Mathematical Sciences, 12(7)(2013), 391-401.

[29] Q.L. Huang, S.H. Wu, B.C. YAng, Parameterized Hilbert-type integral inequalities in the whole plane, The Scientific World Journal, Volume 2014, Article ID 169061, 8 pages.

[30] Z. Zhen, K. Raja Rama Gandhi, Z.T. XIE, A new Hilbert-type inequality with the homogeneous kernel of degree -2 and with the integral, Bulletin of Mathematical Sciences \& Applications, 3(1)(2014), 11-20.

[31] M.TH. RASSIAS, B.C. YANG, A Hilbert - type integral inequality in the whole plane related to the hyper geometric function and the beta function, Journal of Mathematical Analysis and Applications, 428(2): 1286-1308 (2015).

[32] X.Y. HuAnG, J.F. CAO, B. HE, B.C. YANG, Hilbert-type and Hardy-type integral inequalities with operator expressions and the best constants in the whole plane, Journal of Inequalities and Applications (2015), 2015:129.

[33] Z.H Gu1, B.C. YANG, A Hilbert-type integral inequality in the whole plane with a non-homogeneous kernel and a few parameters, Journal of Inequalities and Applications (2015), 2015:314.

[34] M.Th. Rassias, B. YANG AND A. Raigorods KiI, Two Kinds of the Reverse Hardy-Type Integral Inequalities with the Equivalent Forms Related to the Extended Riemann Zeta Function, Applicable Analysis and Discrete Mathematics, 12(2018), 273-296.

[35] Z.Q. WANG, D.R. Guo, Introduction to special functions, Science Press, Beijing, China, 1979.

[36] J.C. KuAng, Applied inequalities, Shangdong Science and Technology Press, Jinan, China, 2004.

[37] J.C. KUANG, Introduction to Real Analysis, Hunan Education Press, Changsha, China, 1996. 